\title{
CAPÍTULO 05: AVALIAÇÃO DA ATIVIDADE ANTIBACTERIANA in vitro DO EXTRATO HIDROMETANÓLICO DA Momordica charantia L. (CUCURBITACEAE) FRENTE A Staphylococcus aureus
}

\section{CAPÍTULO 05: EVALUACIÓN DE LA ACTIVIDAD ANTIBACTERIANA in vitro DEL EXTRACTO HIDROMETANÓLICO DE Momordica charantia L. (CUCURBITACEAE) FRENTE A Staphylococcus aureus}

\section{CHAPTER 05: EVALUATION OF ANTIBACTERIAL ACTIVITY in vitro OF THE HYDROMETANOLIC EXTRACT OF Momordica charantia L. (CUCURBITACEAE) FRONT OF Staphylococcus aureus}

\section{Athila da Costa Silva ${ }^{1}$; Jaqueline Barbosa de Souza ${ }^{2}$; Janeffer Lemberg Messias Barboza Cavalcanti ${ }^{3}$; Davi Lacerda Coriolano ${ }^{4}$; Maria Luiza Ribeiro Bastos da Silva ${ }^{5}$}

DOI: https://doi.org/10.31692/978-65-88970-04-1.58-64

\section{INTRODUÇÃO}

Infecções bacterianas são uma das dez principais causas de morte em todo mundo, e no Brasil representam a sétima principal causa de morte. Segundo dados da Organização Mundial de Saúde (OMS), no Brasil as infecções contraídas em ambientes hospitalares correspondem a cerca de 14\% de todas as internações (WHO, 2017). Estas representam um grave problema de saúde pública, em território nacional, estima-se que 720.000 pessoas são infectadas por ano e destas cerca de 20\% resultam em óbito (Silva et al., 2019).

Um importante patógeno que está relacionado a diversas infecções é o Staphylococcus aureus. É uma bactéria Gram-positiva do grupo Staphylococcus que pode ser encontrada em diversas partes do corpo humano como nariz, garganta, pele e tecidos moles, podendo ocasionar várias patologias desde intoxicação alimentar até endocardite infecciosa. Este microrganismo exibe capacidade de adquirir resistência aos antibióticos, dificultando assim a terapêutica (Cavalcanti et al., 2020).

A utilização de plantas como agentes terapêuticos é uma estratégia antiga que estende até os dias atuais, estima-se que cerca de $85 \%$ da população mundial faz uso de plantas ou seus subprodutos mesmo com os avanços da medicina moderna (Gross 2019). O território brasileiro abriga a maior diversidade de plantas do mundo, com mais de 56 mil espécies descritas, correspondendo a $23 \%$ da vegetação mundial. Todavia,

\footnotetext{
${ }^{1}$ Bacharelando em Biomedicina, UNISÃOMIGUEL, athiladacosta@ gmail.com

2 Bacharelando em Farmácia, UNISÃOMIGUEL, jaquelinebarbosadesouza7@ gmail.con

${ }^{3}$ Bacharelando em Biomedicina, UNISÃOMIGUEL, dudalemberg@gmail.com

${ }^{4}$ Bacharelando em Biomedicina, UFPE, davi.coriolano@ufpe.com

${ }^{5}$ Doutora, UNISÃOMIGUEL, prof.luizabastos@gmail.com
} 
ampla disponibilidade de espécies vegetais, menos de $2 \%$ foi estudada do ponto de vista de aplicação medicinal (Agra et al., 2019).

A Momordica charantia Linn, é amplamente encontrada nas áreas tropicais da América do Sul e Central, Ásia e Leste da África. Apresenta propriedades profiláticas e curativas, cuja aplicação se dá na cicatrização de ferimentos, tratamento de infecções bacterianas, virais e fúngicas, além de atividade antiparasitária, hipoglicemiante e antipirética. (Mahmood et al., 2019). Uma vez que as plantas medicinais apresentam propriedades biológicas como agentes antibacterianos, o presente trabalho tem como objetivo avaliar o extrato vegetal da Momordica charantia Linn frente cepas de Staphylococcus aureus.

\section{FUNDAMENTAÇÃO TEÓRICA}

\section{INFECÇÕES BACTERIANAS}

Infecções bacterianas são condições localizadas ou sistêmicas que decorrem de uma exposição a bactérias ou a suas toxinas. Essas infecções ocorrem a partir da entrada, propagação e multiplicação bacteriana no indivíduo, podendo acometer diferentes órgãos, sendo as principais infecções no trato urinário, respiratório e de corrente sanguínea (Menezes et al., 2016). Causadas por diversas bactérias, mas principalmente por Staphylococcus sp., essas infecções são responsáveis por altos índices de morbimortalidade, persistem por extensos períodos de tempo, e acarretam em aumentos nas despesas dos sistemas de saúde e hospitais, assim se caracterizando como um grande problema de saúde pública global (Vêloso et al., 2017).

\section{Momordica charantia L. (CUCURBITACEAE)}

A família Cucurbitaceae é uma diversa família de plantas composta por mais 90 gêneros e 700 espécies, que apresentam diversas propriedades farmacológicas e estão presentes principalmente em regiões tropicais e subtropicais (Costa et al., 2010). Entre os gêneros que com maior importância econômica e alimentícia no Brasil, destaca-se a Momordica, conhecido popularmente como melão-de-São-Caetano, que abriga 60 espécies, e demonstra-se como fonte potencial de substâncias com atividade antimicrobiana (Silva et al., 2019).

A Momordica charantia L. é uma espécie de planta silvestre, popularmente conhecida no Brasil como melão-de-são-caetano. É utilizada vastamente na medicina tradicional de diversos países, uma vez que apresenta atividade antidiabética, anti-helmíntica, antimalárica, 
antiviral, anticancerígena, e principalmente antibacteriana comprovadas. Seu uso tem sido considerado revolucionário, podendo ser explicado pela presença de compostos biologicamente ativos em sua estrutura, como glicosídeos, saponinas, alcalóides, triterpenos, proteínas e esteróides (Costa et al., 2010).

\section{METODOLOGIA}

Trata-se de uma pesquisa qualitativa e quantitativa do tipo experimental, realizado no Instituto Agronômico de Pernambuco (IPA) e no Centro Universitário São Miguel (UNISÃOMIGUEL), localizados na cidade do Recife no estado de Pernambuco.

\section{MATERIAL VEGETAL}

A planta foi coletada em um terreno situado na UNISÃOMIGUEL. Os exemplares foram conduzidos para depósito no herbário do Instituto Agronômico de Pernambuco com número de comprovante de amostra FIB Nº 73/2019 93692, e identificada como Momordica charantia L. Para preparação do extrato as folhas foram submetidas à secagem em estufa a $45^{\circ} \mathrm{C}$ até peso constante e moída com o auxílio de um moinho.

\section{PREPARAÇÃO DO EXTRATO PARA OS TESTES MICROBIOLÓGICOS}

Uma extração foi realizada com metanol $\left(\mathrm{CH}_{3} \mathrm{OH}\right)$ a $70 \%$. $4 \mathrm{~g}$ da planta em pó foi pesada e adicionada em um frasco âmbar, posteriormente foi adicionado $40 \mathrm{~mL}$ de metanol/água (7:3), homogeneizada e submetido ao processo de maceração e ficando em contato com o solvente por uma semana. Após esse período, foi realizada a filtragem em papel de filtro, armazenado em frasco âmbar e mantido em refrigerador a $4^{\circ} \mathrm{C}$.

\section{AVALIAÇÃO DA ATIVIDADE ANTIBACTERIANA}

Foram utilizadas as bactérias Gram-positivas Staphylococcus aureus ATCC 25923 e S. aureus ATCC 25925, cultivadas em ágar nutriente e incubadas a $35 \pm 2{ }^{\circ} \mathrm{C}$ por $24 \mathrm{~h}$.

Para o método de disco difusão, as bactérias foram ajustadas na concentração de 0,5 da escala de McFarland e semeadas em placas contendo ágar Müeller-Hinton. Foram aplicados $10 \mu \mathrm{L}$ do extrato hidrometanólico de M. charantia em discos de papel filtro secos e esterilizados. Em seguida, os discos foram distribuídos sobre as placas e que incubadas a $35 \pm$ $2{ }^{\circ} \mathrm{C}$ por 24 h. Para o método de poço difusão, foram realizados poços nas placas utilizando furadores de $6 \mathrm{~mm}$ previamente esterilizados. Em seguida, $50 \mu \mathrm{L}$ do extrato hidrometanólico 
de $M$. charantia foi depositado nos poços. As placas foram incubadas a $35 \pm 2{ }^{\circ} \mathrm{C}$ por $24 \mathrm{~h}$. Os resultados foram determinados a partir da leitura dos halos de inibição.

\section{RESULTADOS E DISCUSSÃO}

Para determinação da atividade antimicrobiana dos extratos obtido das folhas do Melão de São Caetano (M. charantia) foram realizados dois métodos microbiológico o disco difusão e o poço difusão frente a duas cepas de Staphylococcus aureus (Tabela 1), foi demonstrada atividade antimicrobiana para as cepas de Staphylococcus aureus na concentração testada de $100 \mathrm{mg} / \mathrm{mL}$. A classificação da atividade antibacteriana foi determinada baseada com os halos de inibição onde halos de inibição $\leq 10 \mathrm{~mm}$ corresponderam a molécula inativa; halos de inibição entre 10 e $13 \mathrm{~mm}$ representou atividade moderada; halos de inibição entre 14 e $19 \mathrm{~mm}$ é ativo e halo $\geq 19 \mathrm{~mm}$ é muito ativo (Qiao, Sun, 2014).

Tabela 1. Avaliação da atividade antibacteriana do extrato hidrometanólico de $M$. charantia pelos métodos do disco e do poço.

\section{Método Classificação Método Classificação}

Disco Poço

\begin{tabular}{lcccc} 
S. aureus ATCC 25923 & $12 \mathrm{~mm}$ & Moderada & $18 \mathrm{~mm}$ & Ativo \\
S. aureus ATCC 25925 & $14 \mathrm{~mm}$ & Ativo & $22 \mathrm{~mm}$ & Muito ativo \\
\hline
\end{tabular}

O uso de plantas medicinais para tratamento de infecções é uma prática antiga, com ampla aplicação em países em desenvolvimento onde há a dependência da medicina tradicional para ampliação das abordagens no tratamento de doenças (Gross et al., 2017). O interesse na utilização de plantas como agentes antimicrobianos tem sido aumentado em virtude do desenvolvimento da resistência bacteriana às atuais terapias, atraindo, assim, atenção da indústria farmacêutica e centros de pesquisas como prováveis fontes de substâncias com espectro de atividade frente esses microrganismos (Pio et al., 2019). Nos últimos anos diversos estudos têm sido realizados com a $M$. charantia L. avaliando seu potencial terapêutico como agente bactericida (Rashid et al., 2017). Alguns dos mecanismos de ação antimicrobiano atribuídos à esta planta incluem o rompimento membranas microbianas, interferindo no metabolismo celular, e inibição da bacteriana (Jabeen et al., 2017). 
De acordo com os resultados identificados no presente estudo, notou-se uma suscetibilidade das cepas bacterianas de $S$. aureus à ação do extrato hidrometanólico, com atividade variando de moderada à muito ativa, corroborando com o estudo de Ceballos, Hoyos e Estrada (2017) que com a utilização de um extrato metanólico extraído das folhas de $M$. charantia obteve inibição de $9,8 \pm 1.2 \mathrm{~mm}$ para $S$. aureus por meio do método de discodifusão, inibição decorrente da atividade sinérgica dos flavonóides e compostos fenólicos presentes na planta que ocasionaram ruptura na membrana da célula bacteriana levando ao extravasamento dos componentes celulares exercendo, assim, atividade bactericida. Ahmed e Noor (2020), com a metodologia de disco-difusão, obteve zona de inibição de $8 \mathrm{~mm}$ e com a do poço obteve $10 \mathrm{~mm}$ respectivamente. O método de poço difusão foi considerado mais efetivo em virtude de que à percolação dos extratos ocorrem de forma mais rápida no meio ágar, levando, assim, à uma maior inibição.

A diferença dos resultados identificados em comparação com o nosso trabalho pode ser explicado tanto em virtude de perda dos metabólitos secundários capazes de inibir o crescimento dos microrganismos, podendo ter acontecido por fatores como a idade da planta, solo, umidade, disposição de nutrientes e armazenamento do extrato, influenciando diretamente na composição fitoquímica e na qualidade dos compostos bioativos, quanto em virtude do perfil fenotípico de resistência das cepas bacterianas (Torre et al., 2020).

\section{CONCLUSÕES}

Os resultados identificados no presente estudo são bastantes promissores, uma vez que a $S$. aureus é uma bactéria que apresenta uma alta capacidade de adquirir fatores de resistência. Porém, se faz necessário mais estudos in vitro e in vivo que avaliem todos os compostos fitoquímicos de forma isolada, a fim de elucidar quais compostos são responsáveis por demonstrar atividade antibacteriana, podendo, no futuro, contribuir para desenvolvimento de um novo medicamento com espectro de ação frente esse microrganismo.

\section{REFERÊNCIAS}

AGRA, A. C. et al. Antimicrobial activity of fixed oil of Allagoptera caudescens (Mart.) Kuntze on pathogenic bacteria. Brazilian Journal of Animal and Environmental Research, v. 2, n. 3, p. 1120-1129, 2019. 
AHMED, Z.; NOOR, A. A. Antibacterial activity of Momordica charantia L. and Citrus limon L. on gram positive and gram negative bacteria. Pure and Applied Biology, v. 9, n. 1, p. 207-218, 2020.

CAVALCANTI, J. L.; SILVA, A. C.; SOUZA, R. J. C. Use of Hibiscus sabdariffa L. and Rosmarinus officinalis L. in the formulation of antibacterial soaps. International Journal of Phytocosmetics and Natural Ingredients, v. 7, n. 1, p. 7-7, 2020.

CEBALLOS, L. C.; HOYOS, F. S.; ESTRADA, H. G. Antibacterial activity of Cordia dentata Poir, Heliotropium indicum Linn and Momordica charantia Linn from the Northern Colombian Coast. Revista Colombiana de Ciencias Químico-Farmacéuticas, v. 46, n. 2, p. 143-159, 2017.

COSTA, J. G. M. et al. Antibacterial activity of Momordica charantia (Curcubitaceae) extracts and fractions. Journal of Basic and Clinical Pharmacy, v. 2, n. 1, p. 45, 2010.

GROSS, A. V. et al. Medicinal plants for the" nerves": a review of ethnobotanical studies carried out in South Brazil. Acta Botanica Brasilica, v. 33, n. 2, p. 269-282, 2019.

JABEEN, U.; KHANUM, A. Isolation and characterization of potential food preservative peptide from Momordica charantia L. Arabian Journal of Chemistry, v. 10, n. 1, p. 39823989, 2017.

MAHMOOD, M. S. et al. Momordica charantia L. (bitter gourd) as a candidate for the control of bacterial and fungal growth. Pakistan Journal of Agricultural Sciences, v. 56, n. 4, p. 1-15, 2019.

MENEZES, J. M. R. et al. Perfil da infecção bacteriana em ambiente hospitalar. Revista de Ciências Médicas e Biológicas, v. 15, n. 2, p. 204-207, 2016.

PIO, I. D. S. L. et al. Traditional knowledge and uses of medicinal plants by the inhabitants of the islands of the São Francisco river, Brazil and preliminary analysis of Rhaphiodon echinus (Lamiaceae). Brazilian Journal of Biology, v. 79, n. 1, p. 87-99, 2019.

QIAO, H.; SUN, T. J. Antibacterial activity of ethanol extract and fractions obtained from Taraxacum mongolicum flower. Research Journal of Pharmacognosy, v. 1, n. 4, p. 35-39, 2014.

RASHID, M. M. O. et al. Characterization of phytoconstituents and evaluation of antimicrobial activity of silver-extract nanoparticles synthesized from Momordica charantia fruit extract. BMC Complementary and Alternative Medicine, v. 17, n. 1, p. 1-7, 2017

SILVA, S. B. et al. Produtos naturais de Momordica charantia L. como moduladores da resistência de Escherichia coli a fármacos antimicrobianos. Agropecuária Científica no Semiárido, v. 15, n. 3, p. 219-223, 2019.

SILVA, E. L. et al. Klebsiella pneumoniae Carbapenamase (KPC): bactéria multirresistente a antibióticos. ReBIS-Revista Brasileira Interdisciplinar de Saúde, v. 1, n. 1, 2019 
TORRE, V. E. et al. Antimicrobial Activity and Chemical Composition of Momordica Charantia: A Review. Pharmacognosy Journal, v. 12, n. 1, p. 213-222, 2020.

VELÔSO, D. S. et al. Incidência de infecções bacterianas e o perfil antimicrobiano utilizado no tratamento dos pacientes de um hospital de ensino. Revista Interdisciplinar Ciências e Saúde-RICS, v. 4, n. 2, 2018.

WHO. World Health Organization. Global antimicrobial resistance surveillance system (GLASS) report: early implementation 2016-2017. Geneva, 2017. 